Iegs well drawn up to the abdomen. The temperature was $104 \cdot 6^{\circ} \mathrm{F}$, the skin was hot and dry, the tongue was coated with a silvery white fur in the centre, the tip and edges were red and cracked; the breath was foul ; the respirations were 28 and shallow; and the pulse was 124, but of fair volume. The thoracic and abdominal organs were apparently natural. The right femoral and inguinal glands were much enlarged, though distinct from one another, and they were surrounded by considerable brawny œdema. The whole tumour measured $3 \frac{1}{2}$ in. by $4 \frac{1}{2}$ in. and was extremely tender. The skin overlying it was slightly reddened and not moveable on the surface of the swelling, but no fluctuation could be detected. The lochia were very free, light yellow and sweet. The external os admitted the little finger; the internal $c s$ was dilated to admit the finger, by which means several small bits of placenta and shreds of membrane were removed. The cavity was washed out with a 1 in 3000 perchloride of mercury solution and similar vaginal douches were ordered twice daily. On the 12th, the morning after admission, the patient was seen by Dr. Yersin, who refused to inject her as he considered her case to be hopeless. The temperature had remained high, but the lochia were sweet and the pain in the bubo was slightly less. The urine was dirty yellow, of specific gravity 1020, slightly albuminons, and neutral. On the 13th, though much improved in the morning, she became very restless towards night and at 11 P.M. complained of severe pain in both iliac regions. On examination no swelling was detected. The temperature in the morning was $102.0^{\circ}$ and in the evening was $104 \cdot 8^{\circ}$. On the 14 th there was no more pain in the abdomen, she looked much better, and the bubo was considerably enlarged in size. The temperature in the morning was $103.0^{\circ}$ and in the evening was $102.4^{\circ}$. On the 15 th, the temperature remaining high, she was given $10 \mathrm{gr}$. of antefebrin in brandy at night. This greatly relieved the headache as well as being effectual in reducing the temperature $3^{\circ} \mathrm{F}$. On the 17th the bubo was opened. Caseous pus and blood escaped. Beyond copious sweating she complained of nothing. There was no pain and no other swellings were detected. The temperature in the morning was $99.6^{\circ}$ and in the evening was $101 \cdot 0^{\circ}$. From this time the patient progressed quite favourably. On the 22 nd the incision in the bubo was considerably enlarged and two more suppurating sacs were opened. On April 1st she was discharged well.

Bacteriological examinaticns of her blood were made on March 12th and 16th, but the agar tubes remained perfectly sterile. On March 17th cultures on slanting agar were made from the caseous pus and yielded many colonies of plague bacilli and a few streptococci, which were examined microscopically.

The treatment in this case was practically the same as in Case 1 and needs no further comment.

I have to thank Dr. Bitter of Cairo and Professor Gaffky for their kindness in allowing me to work in their laboratory and for confirming the bacteriological and microscopic investigations of the above cases. I am also indebted to Assistant Surgeons Lafonde, Netscher, and Macgregor of St. George's Hospital, Bombay, for their help in observing these cases clinically.

Bombay.

Wrgan Medical Society.-A meeting of this society was held on Sept. 8th, 1898, Mr. Wm. Berry, F.R.C.S.I., President, being in the chair.-Dr. Blair read a paper on the Serum Treatment of Puerperal Septicrmia, which he illustrated with copious notes from a successful case in his own practice. The usual methods of treatment were also adopted throughout. Anti-streptococcic serum was used. The serum was best employed early in the disease and then towards evening, and in all cases collapse must be watched for and obviated. The belief was expressed that recovery from puerperal septicæmia treated with serum would be more thorough than with other methods alone.Dr. Blair said it was desirable that the serum should be of standard strength and purity so that definite results could be obtained.--In the discussion on the paper the following gentlemen took part: The President, Mr. Parker, Mr. Jones, Mr. Graham, Mr. Monks, Mr. France, and Dr. Rees and Dr. Benson.-Dr. Blair replied.-A vote of thanks to Dr. Blair for his paper was moved by Dr. Benson, seconded by Mr. Monks, and carried unanimously.

\section{Olinital allotes:}

\section{MEDICAL, SURGICAL, OBSTETRICAL, AND} THERAPEUTICAL.

\section{A NOTE ON THE OCCURRENCE OF CARTILAGINOUS AND BONY NODULES OF THE TONSILS.}

By WyatT Wingrave, M.R.C.S. Eng.,

ASSISTAXT SURGEOY AND PATHOLOGIST TO THE CENTRAL LONDON THROA' AND EAIR IIOSPITAI.

IN an article published in THE LANCET of August 13th last Dr. Hugh Walsham drew attention to the existence of cartilage and bone in the faucial tonsil and expressed the opinion that they were vestigial in origin, whilst Dr. Kanthack believed that they were due to some metaplastic process. I am quite of the view that these cartilaginous masses originate in developmental vestiges and have always considered them to be identical with the subpharyngeal cartilage of Luschka, referred to in Macalister's "Anatomy," but with regard to the bony masses in some instances I am inclined to agree with Dr. Kanthack, since they are generally multiple, being often scattered about the substance of the tonsil and they are often associated with morbid changes in that structure. Still, Dr. Walsham's example of transition proves a possible chondral origin.

My experience is that cartilaginous nodules are by no means rare in this situation. Several years ago I exhibited sections at the British Laryngological and Rhinological Association and in January last further examples at the Laryngological Society of London. ${ }^{2}$ These nodules were found accidentally during the microscopical examination of diseased tonsils-mostly chronic hypertrophy-removed from patients below twenty years of age. Dr. Walsham's were, however, associated in two instances with the more mature ages of twenty-seven and fifty years, Deichert's case being as old as seventy-seven years. As in those cases, the cartilage was hyaline and white fibrous, embedded in a dense connective tissue capsule, sometimes occurring in the fibrous "bed" and sometimes in the lymphoid pulp of the tonsil, but never in the lymph nodules or follicles. I have only found calcification in one instance and this was not truly osseous. It is interesting to note that in Dr. Walsham's cases the tonsils were atrophied and that the bony elements were in excess of the cartilaginous. There must be considerable difficulty in forming a true estimate as to the frequency in the occurrence of these " nodules," since they are generally found by accident; still I have no doubt but that a systematic search will prove them to be much commoner than is generally believed. It is not an unusual experience when operating to find considerable resistance to the guillotine quite disproportionate to the density of the tonsil tissue. This I have in several instances proved, by the aid of a pocket lens and the fingers, to be due to the presence of fibrous and cartilaginous tissue, which was confirmed by the microscope. The fact that all my cases were young sub. jects is, perhaps, sufficient explanation for their being solely cartilaginous, since in the second instance described by Dr. Walsham there was partial ossification. That these nodules may as "vestigial rests" be the possible and probable foci of neoplastic changes must not be ignored, and as they are of somewhat more than transcendental interest further research as to their frequency and association may prove valuable.

Devonshire-street, $\mathbf{w}$.

CASE OF LARGE FATTY TUMOUR.

\section{By J. A. Hamilton, M.B., C.M. Edin.,} LIEUTEYAYT, I.M.S.

As cases of very large tumours are comparatively rare nowadays the following may be of interest. I am away from books of reference at present, but $I$ do not think that

1 A Text-book of Human Anatomy, by Alexander Macalister, 1889, p. 596 . 
fatty tumours often reach such a size as the one described below.

The patient, a Manipuri, came to me in March, 1897, when I was officiating as civil surgeon in Manipur. He said he was forty years of age, but he looked more, and was very thin and feeble. He stated that the tumour had been present for about fourteen years, that it had first appeared on the back of his shoulder in the supra-spinous region, and that it had gradually attained its present position as it increased in size. It now hung from the right side of the thorax, the line of attachment crossing the posterior axillary line obliquely downwards and forwards. Looking at the patient from behind he gave the appearance of a bhisti carrying a musuck. He stated that the tumour had not perceptibly increased in size during the last three years. He had tried all sorts of native medicines and applications, and finally, as he found it in every sense of the term a burden to him, he came to the Civil Dispensary to see if anything could be done for his relief. The nature of the tumour was made out without any difficulty and its removal recommended; to this he gladly consented. Accordingly a few days later I amputated it ; I made an eliptical incision, turned the flaps back, and easily separated the tumour from its surroundings, removing it with most of its skin covering. The only difficulty lay in the number of very large superficial veins which had to be secured and in the size of the tumour, which made it very unwieldy and awkward to handle. I unfortunately made the flaps a trifle small, so, owing to tension, I had to cut two stitches next day, but even with this the wound completely healed within three weeks. The tumour was carefully weighed half an hour after removal and it turned the scale at just over $37 \frac{1}{2} \mathrm{lb}$. I saw the patient two months later. $\mathrm{He}$ was very fit and had put on weight, he could get about easily and had even been playing polo, a thing he had not been able to do for years.

Gantok, Sikkim.

TThe above article was accompanied by photographs of the patient taken before removal of the tumour. It had the appearance of an enormous pyriform mass larger in circum. ference than the man's waist, projecting backwards and sideways so much that it could be seen in whatever position he stood with reference to the observer.-ED. L.]

\section{IPECACUANHA IN A CASE OF EPILEPSY.}

\section{BY C. KNox Bond, L.R.C.P. LoNd., M.R.C.S. ENG.}

THE treatment of epilepsy remains so unsatisfactory that any suggestion derived from the treatment of individual mases of this malady may possess some therapeutic value.

The following note refers to an unmarried woman, aged twenty-nine years, a patient at the St. George's and St. James's General Dispensary, who had been subject to epileptic fits from the age of eight years. When the fits first commenced they were described as "faints," but from the onset of the catamenia they assumed a more serious form, when she was taken to a special hospital for nerve diseases for a period of six months and was said to have received no benefit from treatment. She was then treated at a general hospital continuously for two years and since then has been more or less under treatment at the hands of sereral physicians. On July 14th, 1897, she was admitted to the above institution under the care of Dr. Alfred Eddowes, who found that she had taken continuously for a long period large doses of bromide with out, according to the statement of her mother, diminishing the number or severity of the fits. Dr. Eddowes therefore decided to reduce the bromide to a third of the former dose and added vinum ipecacnanhe to the prescription. A dose of 10 minims was commenced with, increased from time to time as the fits recurred until a dose of 40 minims three times a day was reached. With each increase of ipecacuanha there was a marked improvement in the patient's condition. 'The severity and frequency of the fits had diminished under this treatment until May 3rd, 1898, since when no fits have occurred. The patient's mother stated that her daughter had never enjoyed so long an immunity from fits at any previous period since their commencement.

The reasons which led Dr. Eddowes to adopt this treatment were based, firstly, on his observation in his former private practice as to the value of ipecacuanha in convulsive attacks of children apparently due to gastro-intestinal irritation; and secondly, that it seemed a likely remedy to check the voracious appetite and neglect of mastication so frequently observed in epileptics. The marked improvement with this treatment so noticeable in a very intractable case under my observation for nearly three years leads me with Dr. Eddowes's concurrence to submit this brief note for publication in THE LANCET.

King-street, $W$.

\section{d attitrot}

OF

\section{HOSPITAL PRACTICE, BRITISH AND FOREIGN.}

Nulla autem est alia pro certo noscendi via, nisi quamplurimas et morborum et dissectionum historias, tum aliorum tum proprias collectas habere, et inter se comparare.-MonGaGNI De Sed. et Caus. Morb., lib. iv. Procmium.

\section{GREAT NORTHERN CENTRAL HOSPITAL.}

A CASE OF GASTRO-JEJUNOSTOMY IN WHICH THE ARTIFICIAL OPENING WAS SURROUNDED WITH A TRIPLE ROW OF SUTURES AND LINED WITH MUCOUS MEMBRANE.

(Under the care of Mr. C. B. Lockw0oD.)

THE best method of uniting two portions of the alimentary canal has been much discussed in recent years. There are at present two chief parties; first, those who advocate the employment of only a needle and suture, and those who call in the aid of various mechanical appliances. By a needle and suture it is quite possible to unite two pieces of intestine completely and successfully, but even the most ardent supporters of this method must acknowledge that in some cases at least the process is lengthy. The adrocates of the employment of "apparatus" in enterectomy or gastroenterostomy claim that the duration of the operation is materially shortened. It is true that some little time is saved in the operation, but the presence of the "apparatus" is in itself a danger. In some cases it may be important to terminate the operation at the earliest possible moment; in these a Murphy's button or other "apparatus" may be usefully employed, but if it be possible safely to prolong the operation a simple suture will offer less chance of troublesome complications. The method of suture employed by Mr. Lockwood in the following case is ingenious, and a very thorough joint results; the only possible objection which can be raised is that the operation requires no small amount of time; but practice in the method would go far to obviate this objection. Gastro-jejunostomy is a valuable, though of course only a temporary, method of treatment of cases of malignant disease of the pylorus, in which no attempt at removal can be made. It is also of permanent value in cases of nonmalignant pyloric obstruction, but for this condition a Heineke-Michulicz operation is usually preferable.

The patient, a man, aged fifty-four years, said that he had had syphilis in his youth, but otherwise his history was good. He had not been a hard drinker. In October, 1895, he began to have dyspepsia and pain after food. In November he vomited occasionally after food; soon he began to vomit all solid food; and when he was admitted to the Great Northern Central Hospital on Jan. 1st, 1896, he had commenced to vomit liquids. No blood was seen either in the vomit or in the motions. A rapid loss of weight accompanied this illness, so that he had become exceedingly emaciated and so weak that he had to be carried into the ward. A hard ovoid swelling, the long diameter of which was about 3 in. and the short diameter $2 \frac{1}{2}$ in., was easily felt through the thin abdominal walls beneath the eighth right costal cartilage and in the situation of the pylorus. The stomach was dilated and reached before the level of the umbilicus. A succussion splash could be heard and felt. The tumour of the pylorus was rather tender and moved freely with the descent of the diaphragm. It was soon ascertained that all the fluids which the patient swallowed were vomited mixed with gastric juice 